\title{
Platform-Independent Courseware Sharing
}

\author{
Takao Shimomura \\ University of Tokushima, Tokushima, Japan \\ E-mail:simomura@is.tokushima-u.ac.jp
}

Adriano Montanaro

University of Padua, Padova, Italy

E-mail:montanar@math.unipd.it

\begin{abstract}
Courseware distribution between different platforms is the major issue of current e-Learning. SCORM (Sharable Content Object Reference Model) is one of the solutions for courseware sharing. However, to make SCORM-conformable courseware, some knowledge about HTML and JavaScript is required. This paper presents a SWF (Sharable Web Fragment)based e-Learning system, where courseware is created with sharable Web fragments such as Web pages, images and other resources, and the courseware can be distributed to another platform by export and import facilities. It also demonstrates how to export a subject that contains assignments and problems and how to import the whole subject, only the assignments, or only the problems. The exported meta-information is architecture-independent and provides a model of courseware distribution.
\end{abstract}

Index Terms - Distribution, E-Learning, Export, Import, Sharable

\section{Introduction}

Web-based training is popular around the world, where a large number of people can study at the same time through the Internet anytime and anywhere. There are no limitations of time and space with e-Learning that uses a Web browser. The contents of courseware are presented to learners using multimedia such as text, diagrams, images, animation, music, and videos. They can check the results of their study by themselves because the score is displayed after questions are answered. For example, Moodle [1] is used as an online infection prevention and control program [2] for medical students. A Web-based e-Learning platform [3] for physical education provides sports related courseware which includes physical motions, exercise rules and first-aid treatment. The courseware is represented using digital multimedia materials which include video, 2D animation and 3D virtual reality. Autonomous learning [4] plays an important role in raising students' learning effect and innovation ability. W. Song, et al. developed a system that consists of a management system, a learning system, a homework system and an interactive answering system. Semantic Web technology [5] in e-Learning offers various semantic-based services to the students and the instructors. Students can perform semantic querying for learning materials.

The major issue of current e-Learning is the difficulty of resources sharing and searching, which is mostly caused by the weak-semantic learning resources and the poor sharing mechanism. To solve this problem, for example, by applying ontology and Web services technology [6] to e-Learning, the learning resources are well defined and information exchanging is supported. AICC [7] develops guidelines for aviation industry in the development, delivery, and evaluation of computerbased training and related training technologies. It assists airplane operators in development of guidelines which promote the economic and effective implementation of computer-based training media and develops guidelines to enable interoperability. Qu and Nejd1 [8] re-designed all learning resources contained in an existing Java course according to SCORM (Sharable Content Object Reference Model) [9] so that they can be exchanged between different learning management systems. A Web-based SCORM run-time environment was also implemented using JSP, Java Servlet, and JavaScript, which is able to dynamically render course structure into its corresponding Web presentation on the basis of predefined SCORM content packaging application profiles. However, to make SCORMconformable courseware, some knowledge about HTML and JavaScript is required. Li and Zhang [10] failed to add some useful resources or contents from SCORM to Moodle because of the lack of interoperability between SCORM and Moodle. They needed to implement adding, editing, deleting and moving those resources in Moodle. On the other hand, WebOL [11] creates some questions based on Web pages and packages them so that they can be available in another platform. It generates HTML and JavaScript code and maintains all resources in a single directory ready for distribution. A project can be run from a Web browser by opening the start-up page created by WebOL. However, it does not contain any features for the recording of assessment results. 
This paper presents a SWF (Sharable Web Fragment)-based e-Learning system Apty [12, 13], where courseware is created with sharable Web fragments such as Web pages, images and other resources, and the courseware can be distributed to another platform by export and import facilities. It also demonstrates how to export a subject that contains assignments and problems and how to import the whole subject, only the assignments, or only the problems. The exported meta-information is architecture-independent and provides a model of courseware distribution.
The remainder of this paper is organized as follows: Section 2 describes conventional SCORM-based eLearning systems. Section 3 explains the SWF-based eLearning systems this paper proposes. Section 4 presents export and import methods of courseware. Section 5 demonstrates examples of courseware distribution. Section 6 discusses the evaluation of the system. Finally, Section 7 summarizes the paper.
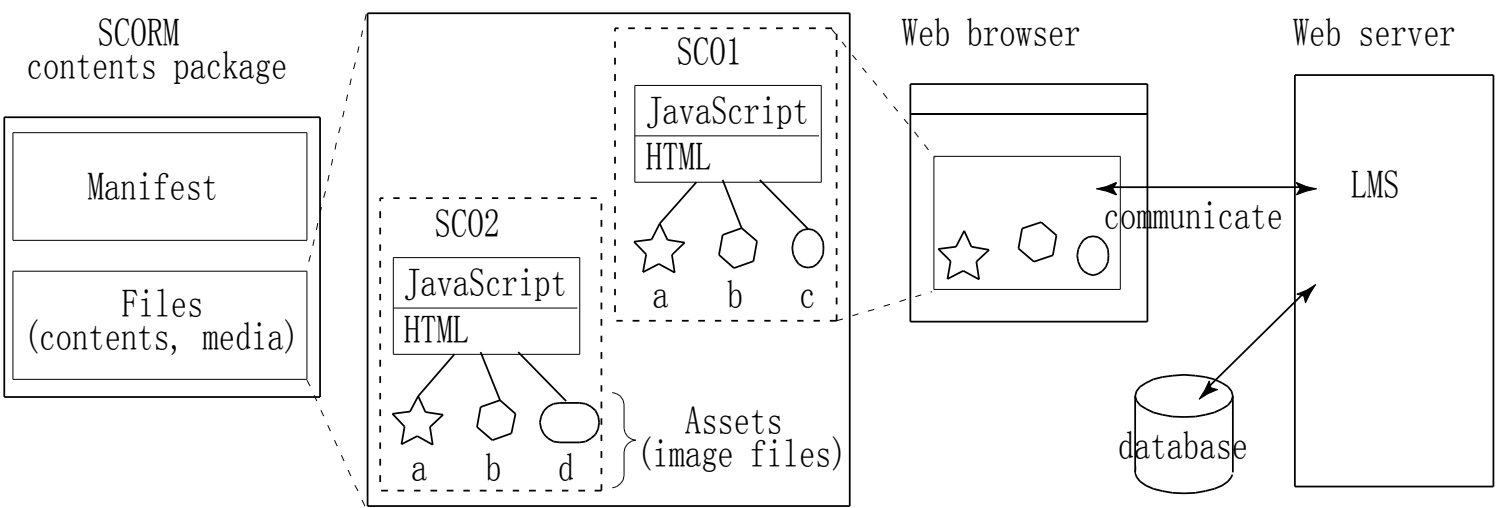

Fig. 1: Courseware with SCORM

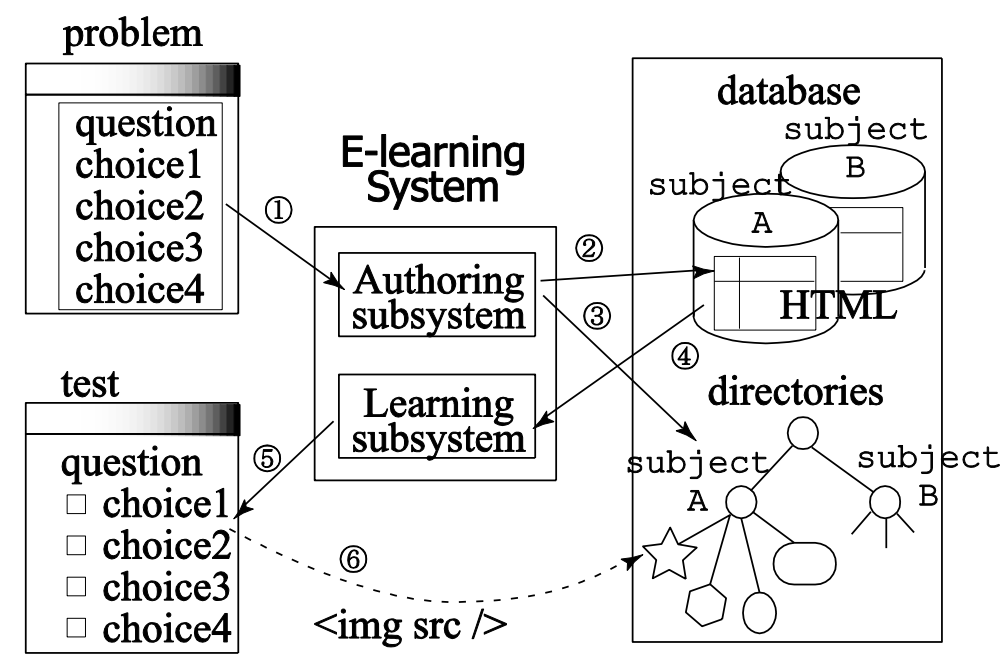

Fig. 2: E-learning system with SWF (Sharable Web Fragments)

\section{SCORM-Based E-Learning Systems}

SCORM (Sharable Content Object Reference Model) is standards for e-learning software products. It tells programmers how to write their code so that it can work with other e-learning software. It defines how courseware and LMSs (Learning Management Systems) communicate with each other. As shown in Fig. 1, SCORM content package consists of a manifest and files, which contain several SCOs (Sharable Content Objects). An SCO contains a Web page and some resources such as image files. The Web page of a SCO contains HTML code and JavaScript code to communicate with an LMS. Each SCO will be displayed as a Web page in a Web browser window by the LMS. When an SCO is displayed, its JavaScript code communicates with the LMS, for example, to send students' scores and receive their total scores. Each SCO must be independent from each other and cannot refer to the other SCOs or their resources. If same resources are used by multiple SCOs, they will need to be located in each of the SCOs or in their parent SCO, which might affect the hierarchy and the navigation of the courseware. As SCOs must define some JavaScript code, knowledge about HTML and JavaScript is required to create them. Logic for scoring tests must be programmed by a person who creates SCOs. On the other hand, SCOs can be distributed to other SCORMbased e-Learning systems without any transformation. 


\section{SWF-Based E-Learning Systems}

This section describes e-Learning systems that do not use SCOs (Sharable Content Objects). These types of eLearning systems work with SWFs (Sharable Web Frag ments). Figure 2 shows the system configuration of one of these types of e-Learning systems. The system consists of an authoring subsystem and a learning subsystem. With the authoring subsystem, teachers can easily create some problems. (1) For example, a problem consists of a question statement, several choices, and advice to solve this problem. These materials are created by using a Web browser and turn into HTML code. The materials may include other resources such as images and hyperlinks to some PDF files or other Web pages. (2) The authoring subsystem stores these materials into DB (database) tables, and (3) copies the resources to appropriate directories.

(a) Assignments being created

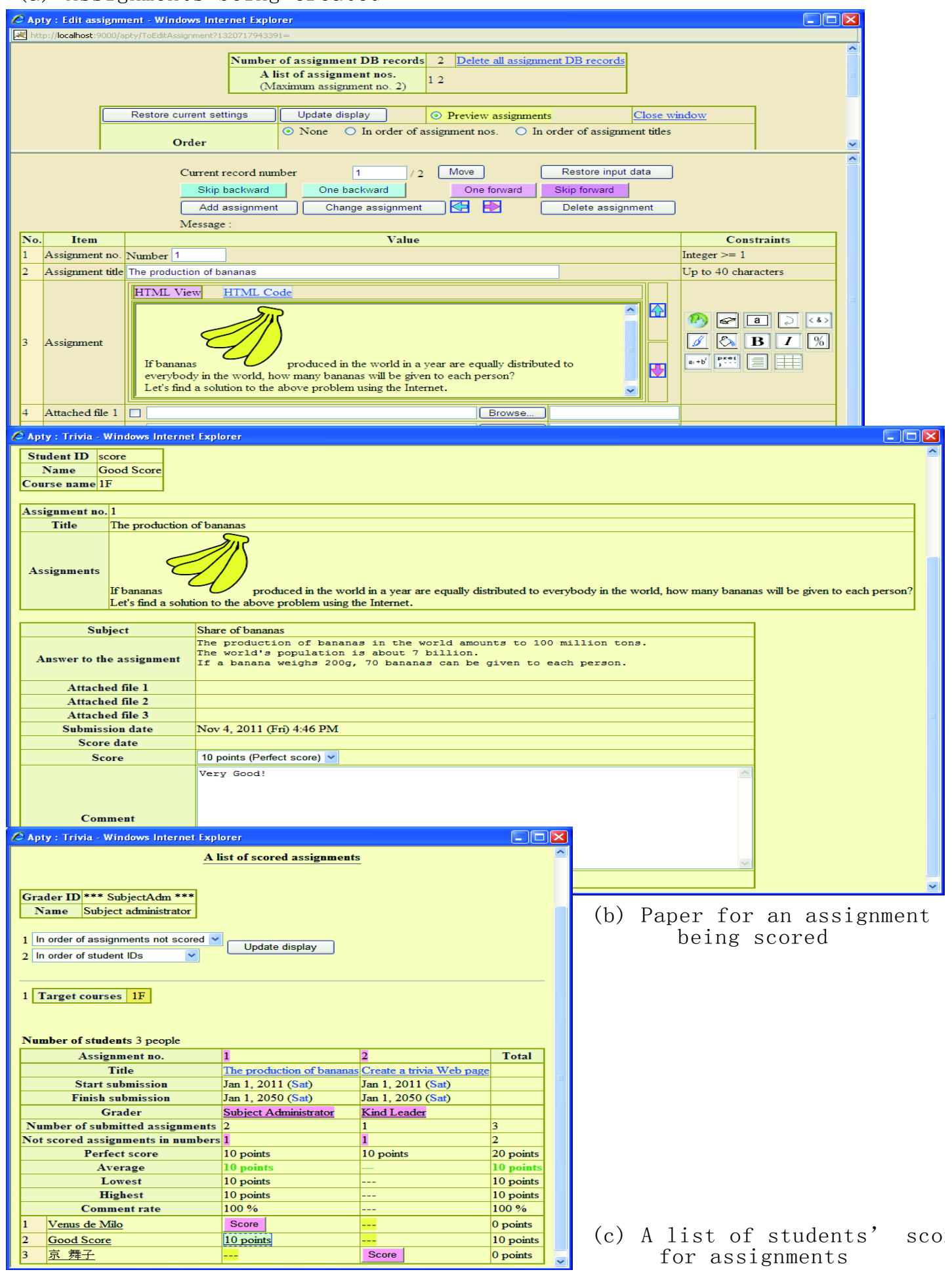

Fig. 3: Create assignments and score papers 
The learning subsystem will present the created problem when a test is conducted. (4) From the conten ts of the DB tables, (5) a test Web page will be automatically generated. (6) Then, as this Web page refers to some resources in the directories on the server side by using <img src/> or <a href/> tags, those resources will be downloaded to the client side to be viewed. The courseware is stored in both of DB tables and files on the server side. Figure 3 illustrates (a) how teachers create assignments, (b) how they score the papers for the created assignments, which have been submitted by students, and (c) a list of students' scores for the assignments. Figure 4 demonstrates a fourchoice question being created by using a Web browser, a test to be conducted with the created question, and the scored test result. The earth image has been uploaded from the client side to the server side when it is inserted into the question statement. To conduct tests, the teachers have only to create four-choice questions. The other parts of the test Web page have been automatically generated by the learning subsystem.

(a) Problems being created

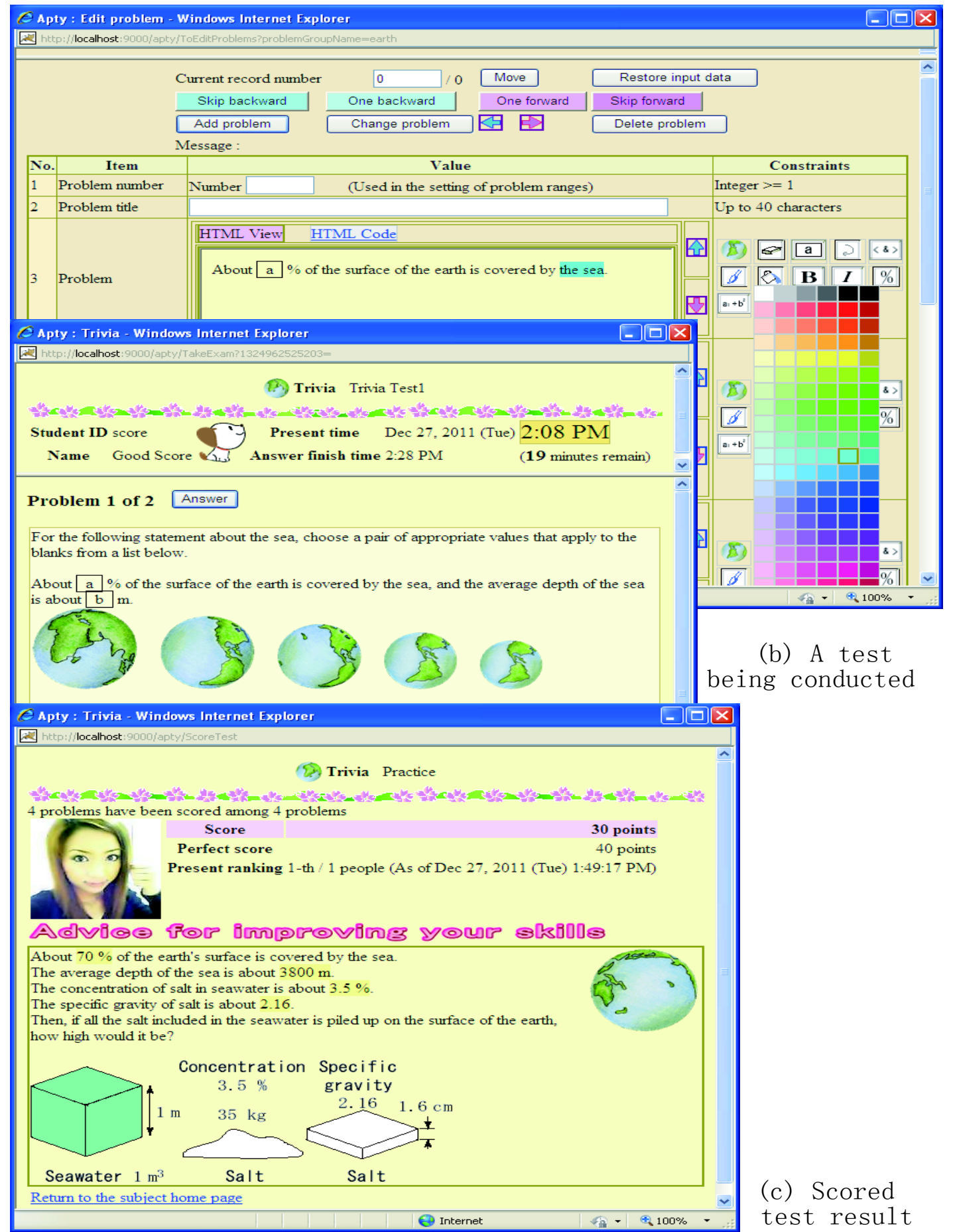

Fig. 4: Create problems and conduct a test 


\section{Exports and Imports of Subjects, Assignments and Problems}

This section presents a method for distributing SWFbased courseware to another platform.

\subsection{Courseware Transfers}

The SWF-based courseware that is once exported can be imported by another SWF-based e-Learning system. Among several subjects one e-Learning system manages, any one of them can be exported for distribution. The exported subject includes courseware materials generated from DB tables and other resources copied from directories on the server side. This exported subject will be transferred to another platform to be imported. Once the exported subject is imported by another e-Learning system, this subject can be used in the same way as the other subjects that originally exist in that e-Learning system. Figure 5 shows transferred materials between two e-Learning systems. A subject is exported into the export directory in an eLearning system (source). For another e-Learning system (target) to import this subject, this exported subject needs to be located in the import directory of that e-Learning system. The figure explains how to subject $\mathrm{A}$ is exported and then imported as subject $\mathrm{X}$ into anothere-Learning system.

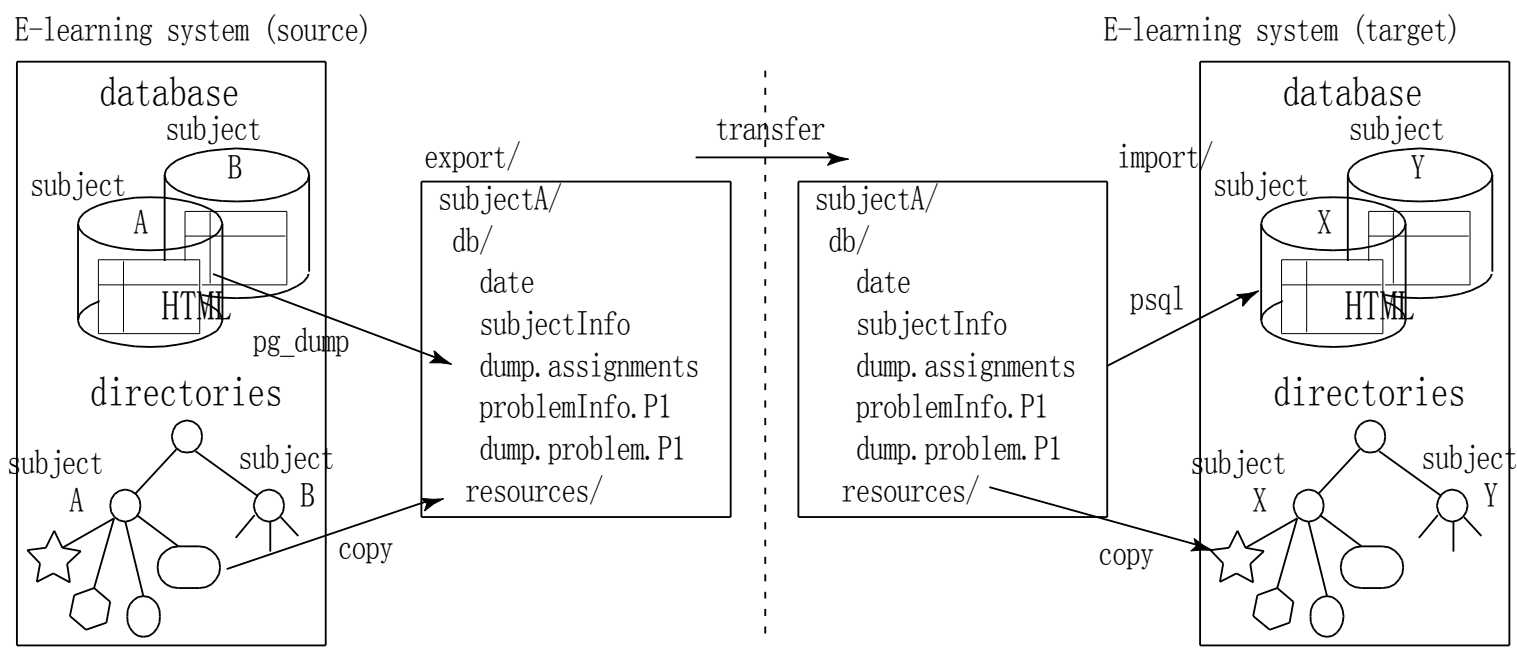

Fig. 5: Distribution of courseware to another e-Learning system

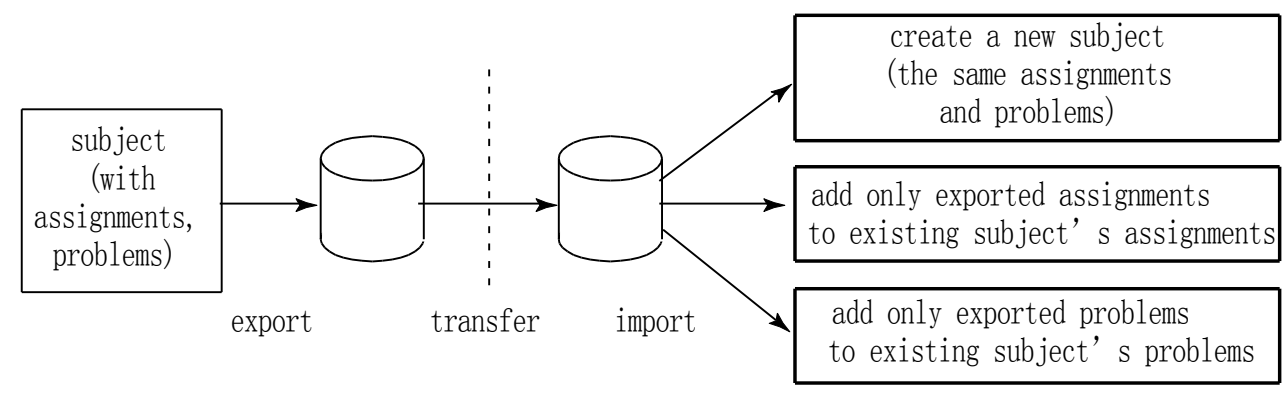

Fig. 6: Automatic export and import of courseware

\subsection{Transferred Materials}

The e-Learning system Apty this paper presents consists of two servers, a Tomcat [14] server (Web server) and a Postgresq1 [15] server (DB server). An exported subject contains materials generated from DB tables by using pg_dump commands, and resources copied from directories. The contents of file "date" indicates the date and time when the subject was exported. They indicate the number of milliseconds since January 1, 1970. To display the date and time according to the locale selected by an admin istrator, the "date" file contains this type of number. The date and time will be shown as "Nov 13, 2012 (Tue) 10:18 AM" in locale "en (English)", "13-nov-2012 (mar) 10.18" in locale "it (Italian)", and "2012/11/13 (火) 10:18" in locale "ja (Japanese)".

File "dump.problem.earth" contains the psql command sequence generated by using a pg_dump command. It will be used to recover the contents of DB table "problemearth", which contains several fourchoice problems. File "problemInfo.earth" contains the meta-information of DB table "problemearth", which contains problem group name "earth", problem group title "Earth", the number of choices, and so on. File "subjectInfo" contains the meta-information of subject 
"trivia", which contains subject name "trivia", subject title "Trivia", locale "en", and so on. These pieces of meta-information will be used as default values when the subject is imported, and then they can be changed as the administrator of this subject likes before he or she clicks on the "import" button.

The whole subject is exported at a time as shown in Fig. 6. On the other hand, when the exported subject is used to be imported, the whole subject, only assignments, or only problems can be imported. The exported assignments and problems will be added to the existing ones in another subject. To distribute courseware to different platforms, the contents of DB tables must be independent from those platforms. For this reason, for example, file path information is stored as URL format in the DB tables. A file path "image \problearth.png" in Microsoft Windows will be stored as "image/prob/earth.png".

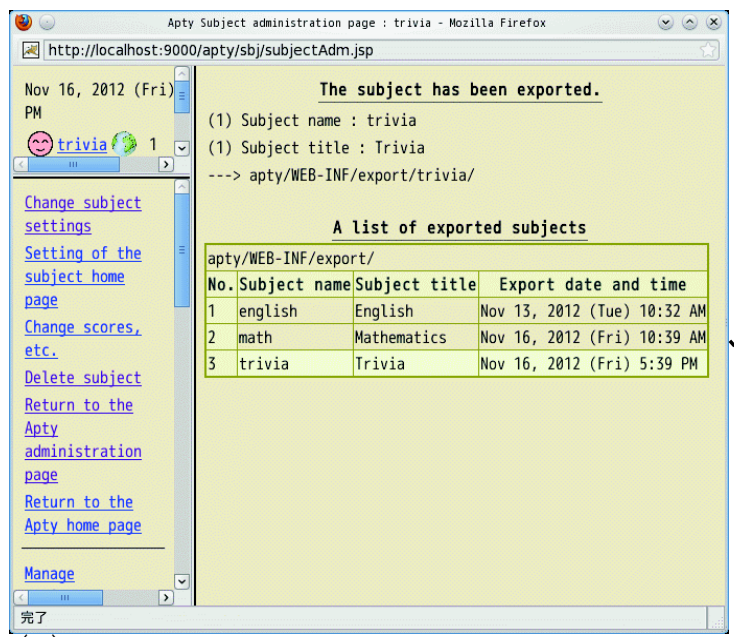

(a) Subject export

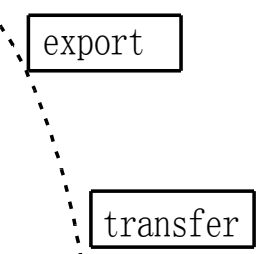

on a Linux server

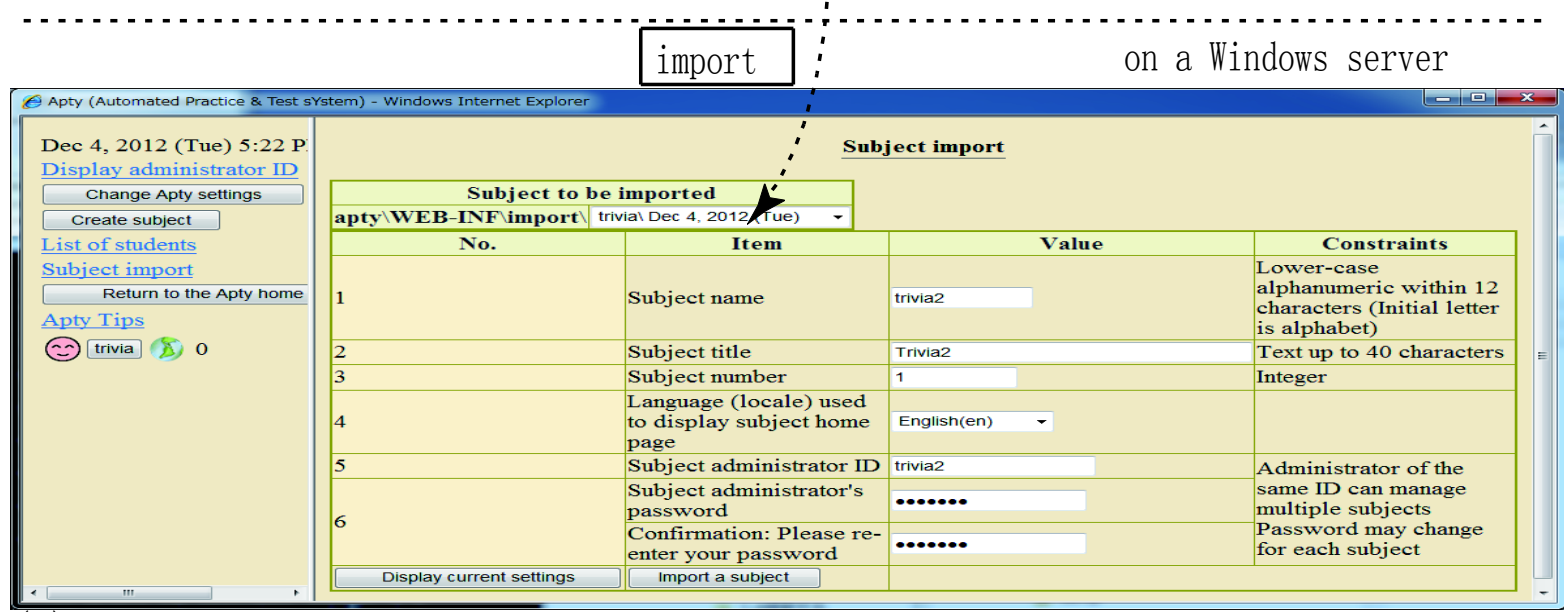

(b) Subject import

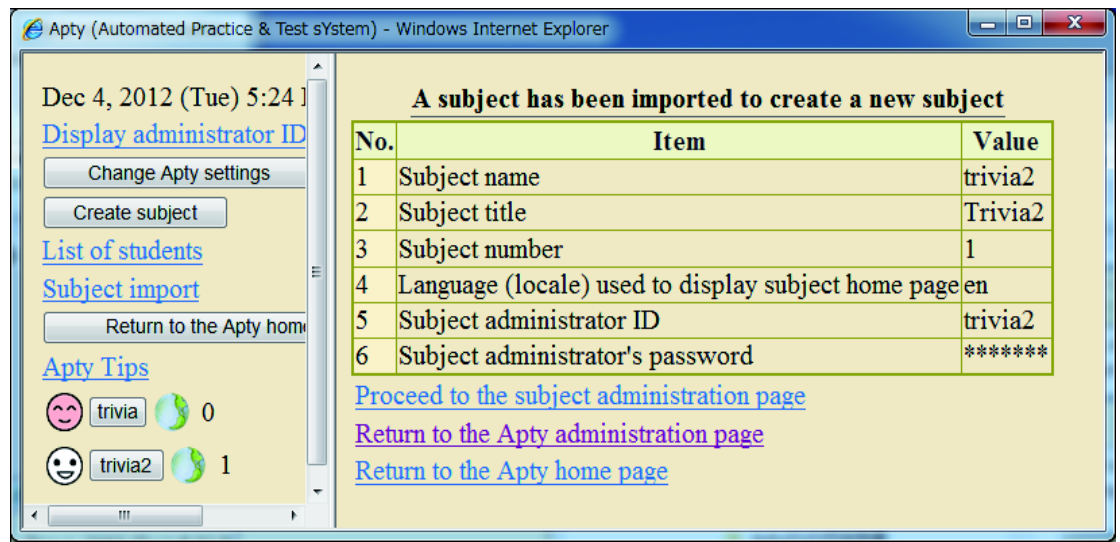

(c) Imported subject

Fig. 7: Automatic export and import of a subject 


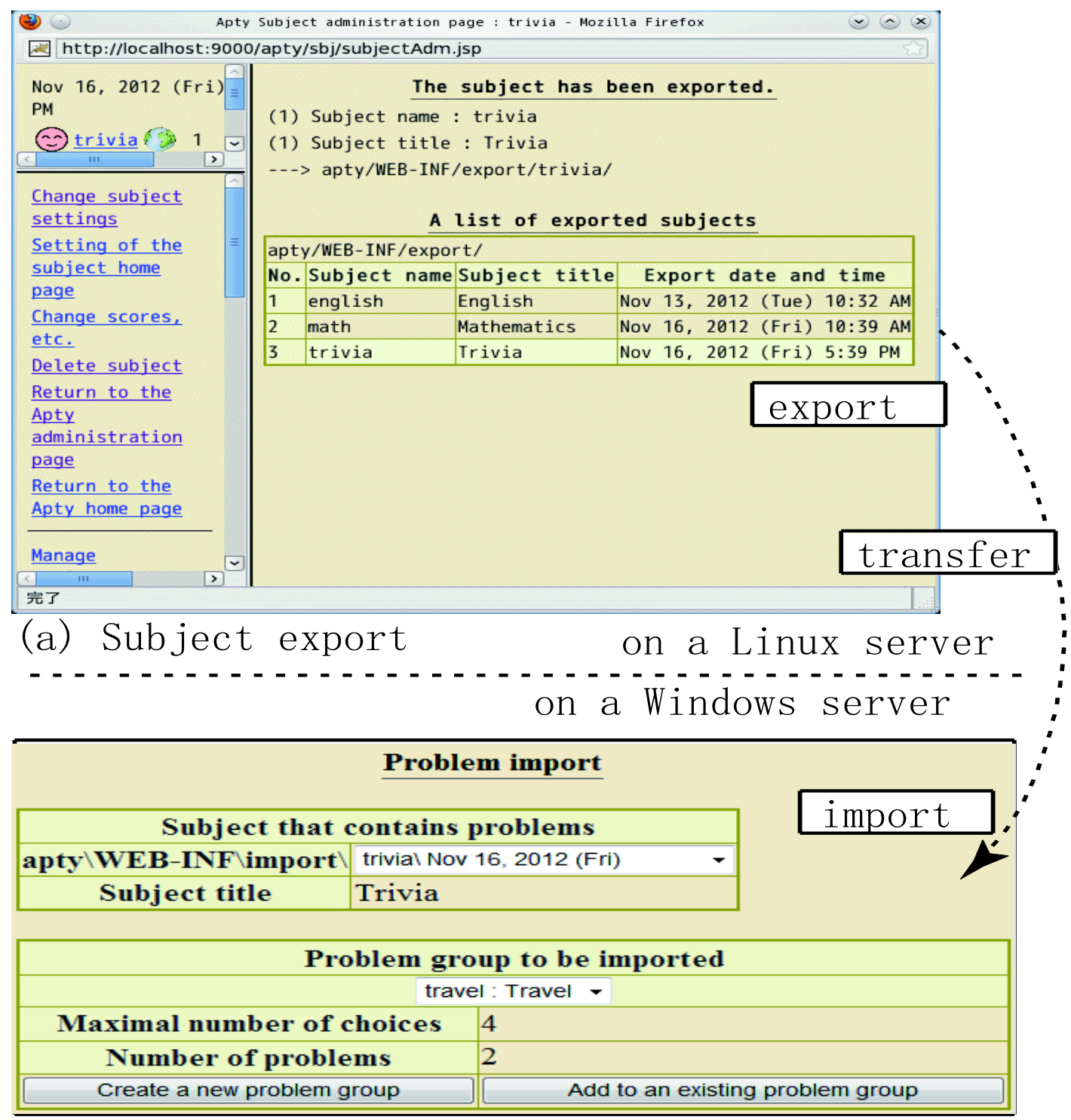

(b) Problem import

\begin{tabular}{||c|c|c|}
\hline \multirow{2}{*}{ Subject } & \multicolumn{3}{|c|}{ Additional import of problems } \\
\cline { 2 - 3 } & Subject name & trivia \\
\hline \multirow{4}{*}{ Problem group } & Problem group name & travel \\
\cline { 2 - 3 } & Problem group title & Travel \\
\cline { 2 - 3 } & Maximal number of choices & 4 \\
\cline { 2 - 3 } & Number of problems & 2 \\
\hline
\end{tabular}

Problem group to which the imported problems will be added

\begin{tabular}{|c|c|c|c|}
\hline No. & Item & Value & Constraints \\
\hline 1 & Problem group name & travel : Travel & - \\
\hline 2 & Number of choices & 4 & \\
\hline 3 & Maximal problem number & 2 & \\
\hline 4 & Increment added to problem numbers & 10 & Integer $>=2$ \\
\hline & Display current settings & \multicolumn{2}{|c|}{ Import problems } \\
\hline
\end{tabular}

(c) Additional import of the chosen problems

Fig. 8: Automatic import of exported problems 


\subsection{Transformation URLs in HTML Code}

The materials of the courseware may include other resources such as images and hyperlinks to some PDF files or other Web pages. These resources are referred to by using <img src/> or <a href/> tags. The SCORMbased e-Learning systems use resources under the same directory of SCOs, which are referred to as relative path names like <img $s r c="$ earth.png"/> or <a href=" memo.pdf"/>. On the other hand, the SWF-based e-Learning systems can refer to any resources in the corresponding subject directories, and those resources are referred to as something like <img $\mathrm{src}=" /$ apty/subjects/subjectA/image/earth.png"/> or $<\mathrm{a}$ href="/apty/subjects/subjectA/doc/memo.pdf"/>. When the materials are imported to another subject "subjectX", these references will be auto matically transformed into <img src="/apty/subjects/subjectX/image/earth.png"/> or <a href="/apty/subjects/subjectX/doc/memo.pdf"/>. This transformation can be automatically performed by applying a regular expression.

The corresponding res ource files will be copied to the appropriate locations of the subject "subjectX" directory. When problems are imported and added to a target eLearning system, if they refer to the files whose names are the same as existing files in the target e-Learning system, those file names will be automatically transformed into other ones. For example, if subject "subjectX" has an image file "image/earth.png", the imported file's name will be automatically changed to "image/earth.imported.0.png" The references to this imported file will be also automatically transformed to "/apty/subjects/subjectX/image/earth.imported.0.png".

\section{Examples of Courseware Distribution}

Any of the whole subject, assignments, and problems can be imported. Figures 7 and 8 demonstrate an example of transferring courseware from a Linux platform to a Windows platform, where Fig. 7 shows how to import the whole subject and Fig. 8 shows how to import problems. Figure 7 (a) shows the result of exporting subject "trivia". It also shows that other subjects "english" and "math" have already been exported and exist in the export directory. By using some facility such as ftp or scp, this exported subject will be transferred from the Linux platform to the Windows platform. Figure 7 (b) shows the procedure of importing a subject to create a new subject. First, a subject to be imported is chosen, and then some information for the new subject is specified. When the "Import a subject" button is clicked on, the imported subject will become the new subject, where the assignments and problems included in the imported subject will become available in the new subject of the target e-Learning system.

Figure 8 (a) also shows the result of exporting subject "trivia". Figure 8 (b) here shows the procedure of importing problems. First, a subject is chosen, and then a set of problems in the subject is selected. When the "Add to an existing problem group" button is clicked on, as shown in Fig. 8 (c), the problem group can be selected to which the imported problems will be added. As some new problems are added into the existing problem group, the problem numbers of these added problems will be incremented by 10 as indicated in the figure. As a result, these new problems will become available in the target e-Learning system.

\section{Evaluation}

In SWF-based e-Learning systems, everyone can easily make courseware by using a Web browser. They are not required to have knowledge about HTML or JavaScript. In addition, the created courseware can be distributed to another e-Learning system by the export and import facilities as described. Instead of these facilities, if courseware is manually transferred to another e-Learning system, it will take a lot of procedures. First, dump DB tables by using pg_dump commands, and transfer the dumped files and subjectrelated resource files to the target e-Learning system. In the target system, create DBs and generate DB tables from the transferred dumped files by using psql commands. Furthermore, transform URLs of HTML code contained in the DB tables. The export and import facilities have saved these laborious procedures.

\section{Conclusion}

This paper has presented export and import methods for courseware sharing. In SWF-based e-Learning systems, courseware can be easily created by using a Web browser without any knowledge about HTML or JavaScript. The courseware can be easily distributed to another e-Learning system. Because the exported subject is architecture-independent, it will be useful even when courseware is distributed to an e-Learning system that has a different architecture. The e-Learning system this paper has presented will be available to anyone at http://apty.org/.

\section{References}

[1] Dougiamas, M.: Moodle, http://moodle.org/ (2012).

[2] O' Neill, E., Stevens, N., Clarke, E., Cox, P., O' Malley, B. and Humphreys, H.: Use of e-learning to enhance medical students' understanding and knowledge of healthcare-associated infection prevention and control, Journal of Hospital Infection (2011).

[3] Huang, C., Chin, S., Hsin, L., Hung, J. and Yu, Y.: A Web-based E-learning Platform for Physical Education, Journal of Networks, Vol. 6, No. 5, pp. 
721-727 (2011).

[4] Song, W., Cao, S., Yang, B., Song, K. and Wu, C.: Development and Application of an Autonomous Learning System for Engineering Graphics Education, J. Modern Education and Computer Science, Vol. 1, pp.31-37 (2011).

[5] Joshi, N.: Semantic Web-driven e-Learning System,DESIDOC Journal of Library \& Information Technology, Vol. 31, No. 4, pp. 213216 (2011).

[6] Wu, G. and Wang, Y.: Research on E-Learning System Prototype Based on Semantic Web Service Technology, Computing and Intelligent Systems, pp. 247-254 (2011).

[7] AICC: Aviation Industry Computer-Based Training Committee, http://www.aicc.org/ (2012).

[8] Qu, C. and Nejdl, W.: Towards interoperability and reusability of learning resources: A SCORMconformant courseware for computer science education, Proc. of the 2nd IEEE International Conference on Advanced Learning Technologies (IEEE ICALT 2002), Kazan, Tatarstan, Russia (2002).

[9] SCORM: Sharable Content Object Reference Model, http://www.adlnet.org/ (2012).

[10] Li, Q. and Zhang, J.: Preliminary Study on Extracting SCORM Contents to MOODLE, Circuits, Communications and System (PACCS), 2011 Third Pacific-Asia Conference on, IEEE, pp. 1-3 (2011).

[11] Harper, R.: Delivery of courseware, tutorials and formative assessment with WebOL, International Journal of Innovation in Science and Mathematics Education, Vol. 11, No. 1 (2012).

[12] Shimomura, T. and Montanaro, A. et al.: Easy, Enjoyable, Effective E-Learning, Nova Science Publishers, Inc., New York (2008).

[13] Montanaro, A., Ikeda, K. and Shimomura, T.: GAME-ORIENTED STIMULATING ELEARNING, 6th International Technology, Education and Development Conference (INTED2012), pp. 4221-4228 (2012).

[14] The Apache Software Foundation: Apache Tomcat, http://tomcat.apache.org/ (2012).

[15] The PostgreSQL Global Development Group: PostgreSQL, http://www.postgresql.org/ (2012).
Authors' Profiles

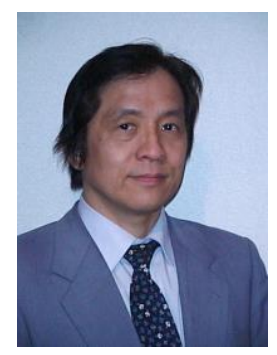

Takao Shimomura: Professor of Dept. of Information Science and Intelligent Systems at the University of Tokushima in Japan. He was a senior research engineer at NTT Soft ware Laboratories from 1975 to 1995 and a guest associate profes sor at the Graduate School of Information Systems of the University of Electro-Communications from 1992 to 1994. His research interests include software design automation, program visualization, and automated debugging. He has a BS from Kyoto University, an MS from Tohoku University, and a $\mathrm{PhD}$ from Tokyo Institute of Technology. He is a member of IPS Japan, IEICE Japan and ACM.

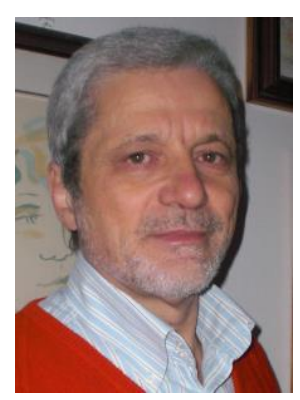

Adriano Montanaro: Professor of Dept. of Mathematics at the University of Padua in Italy. He received the Degree in Mathematics at the University of Padua, Italy with a thesis on Modal Logic. Author of several papers in Continuum Mechanics and Thermodynamics, related with constitutive equations in thermo-electroelasticity, wave propagation in elastic, initially stressed, and internally constrained media, propagation of discontinuities in piezoelectric media, controllability of mechanical systems. The teaching activity is developed at the University of Padua in the degree courses of mechanical and aerospace engineering (courses of Rational Mechanics and Analytical Mechanics) and at the Ph.D. School in Civil and Environmental Engineering Sciences (course of Mathematical Methods).

How to cite this paper: Takao Shimomura, Adriano Montanaro,"Platform-Independent Courseware Sharing", International Journal of Information Technology and Computer Science(IJITCS), vol.5, no.5, pp.1-9, 2013.DOI: 10.5815/ijitcs.2013.05.01 